Evaluation by the trainees of our courses has always been carried out, and we have much modified them in the light of comments received. Trainees have consistently reported the use of videotape as being invaluable as a training procedure, and as a means of gaining a great deal of information which could not be acquired in any other way. Without videotape providing information, models and feedback we could not run the courses in the economical way that we do, and they would not be so successful.

\title{
Teaching Medical Students to Interview Psychiatric Patients
}

\author{
By Peter Maguire, Withington Hospital, Manchester
}

If medical students are to be effective in clinical practice they must acquire the skills needed to put patients with psychiatric problems at ease, to promote trust and confidence, and to elicit an accurate and relevant history. Unfortunately, there is considerable evidence that traditional methods of medical training fail to equip them with these essential skills.

To assess their skills, 50 medical students about to take final examinations were each asked to interview a cooperative psychiatric patient. They were given 15 minutes to obtain a history of the presenting complaints. The interviews were videotaped, and the interviewing techniques rated on a 5-point scale. The information obtained was also rated according to category and completeness.

This analysis revealed serious deficiencies in history-taking skills (Maguire and Rutter, 1976). Eighty per cent of the students avoided personal aspects such as the patient's relationships, sexual adjustment, feelings about his illness, and the possibility of suicidal ideas. They ( 86 per cent) made little effort to date key events in the patient's history or to determine what treatments he had received. While all the patients gave clear verbal clues about their problems, most students ( 74 per cent) failed to pick up more than a fraction of these. Even when they established the key complaints they commonly (62 per cent) failed to clarify their true nature and extent. The students obtained only a third of the relevant data that were judged to be 'easily obtainable' within the time allowed.

These deficiencies are not remedied by later clinical training and are equally evident in general practitioners, general physicians and surgeons (Sanson-Fisher and Maguire, 1980). Moreover, Goldberg and his colleagues have established a strong link between this lack of skills and the failure of general practitioners to recognize and treat much psychiatric illness which presents to them (Goldberg et al, in press; 1980). It is important, therefore, to consider why students and doctors lack these skills and how they can better acquire them.

Most undergraduate teaching is based on the apprenticeship method. When attached to a psychiatric firm students are given a handout which simply lists the questions they should ask when taking a history. As clinical clerks they then interview both new and old patients. Their ability to take a history is judged on the histories they write up and present. Such a judgement takes no account of how the student actually conducted his interview or of what the patient thought of the student. Like the initial handout it focuses on content, and is inevitably misleading. So both teacher and student remain unaware of any deficiencies. Most teachers were taught by using a similar method and are unaware of its shortcomings or reluctant to admit them.

\section{The development of more efiective methods}

History-taking skills could be acquired more easily if the training programme included the following components: the provision of handouts detailing questions to be asked and the techniques to be used; a chance to practise under conditions of direct observation within a strict time limit, and feedback about performance.

To evaluate such a programme, 24 medical students were randomly allocated to routine clinical training (control) or to routine training plus the training programme (experimental) (Rutter and Maguire, 1976). Students in both groups conducted a short practice interview which was videotaped. The experimental students were then given a handout, watched their taped interview and received individual feedback about their performance. A week later both groups of students conducted a second practice interview. The experimental students obtained nearly three times as much accurate and relevant information as the control students.

A second study was conducted to see if videotape feedback was a crucial component of training. Students were randomly allocated to training by practice, presentation of a handout and video feedback, or to training by practice and handout alone. No differences were found between the groups in the amount of data they obtained. Provision of a clear model of what and how to ask questions coupled with practice under strict conditions led, it seemed, to students obtaining more accurate histories.

This encouraged us to prepare videotapes more clearly demonstrating history-taking methods. Students who viewed these tapes in conjunction with the handouts and practised 
history-taking under direct observation showed a greater gain in performance than those trained by traditional methods (Maguire et al, 1977).

\section{The role of feedback}

The effectiveness of these courses and their superiority over traditional approaches was encouraging. A further study was therefore conducted to see if more frequent feedback would prove even more effective (Maguire et al, 1978).

Forty-eight students who were receiving conventional training in history-taking were drawn randomly into groups of four during their clerkship in psychiatry. Three students in each quartet were assigned to one of three feedback methods: feedback by tutors using video; audio-tape replays; and ratings of the student's performance. The fourth student was given no additional teaching and served as a control. Before training began, each of the three 'feedback' students in a quartet interviewed the same patient to elicit presenting complaints. The control student saw the patient a day later.

After the interviews, the three feedback groups met with a tutor, received a handout describing the questions and techniques, and engaged in discussion about them. A few days later each student in the video group watched a video replay of his first interview together with his tutor and then discussed it. Students in the audiotape group were given feedback in sound only. The remaining students received feedback from a tutor unaided by video or audiotape. The tutor had previously seen a video recording and rated the students' interviewing performance. He then discussed his ratings with the student. The same amount of time was spent by the tutor in each of the three feedback conditions. This procedure was repeated after two further practice interviews. Control students practised as often but received no further training.

Each student conducted a final interview to assess posttraining performance. All students in a quartet again saw the same patient, different to the one seen on previous occasions. Video recordings of interviews conducted before and after training were rated by judges blind to the experimental conditions. It proved possible to measure performance reliably. Agreement between raters was satisfactorily high for both technique and information elicited. There was also good agreement when the ratings and reratings done six months later were compared.

Results: All three feedback groups showed a significant gain in their ability to elicit accurate and relevant information, but only video and audio feedback conditions led to significant improvement in technique. This better performance in technique was not attributable to any order effects, differences in the number or types of patients, or to students' beliefs that their training was better than that of the others. Video feedback was especially useful in helping students learn techniques of control, how to avoid needless repetition of topics, ask personal questions, and detect and respond to the patient's verbal leads.
The failure of control students to show any significant gain in history-taking skills was striking and confirmed the ineffectiveness of traditional teaching methods.

\section{Teaching in small groups}

The provision of individual feedback proved time-consuming and prompted two questions: would this teaching be as effective in small groups, and could students teach themselves? In an attempt to answer these questions, students were randomly allocated to one of the following conditions: 1. Individual feedback - after each of three practice interviews the student watched and rated a video reply.

2. Individual supervision-the student watched and discussed a video replay with a supervisor.

3. Group feedback - four students met together and saw their performance on video.

4. Group supervision - a supervisor sat in on a group watching their interviews on video.

After the initial practice interview all students were shown a videotape which discussed and demonstrated techniques to be learned. Supervision proved to be the crucial component: supervised students acquired more of the desired skills than those not supervised. Moreover, little was lost by conducting feedback in groups or allowing a student in a group only one opportunity to watch his own interview. Unsupervised students were less able to analyse their strengths and weaknesses in the context of the skills being taught. Students in general considerably overestimated their performance when compared with the judgements of 'expert' raters.

Our finding that history-taking skills could be taught effectively in small groups was encouraging because it was much more feasible. However, the reliance on video feedback meant that practice had to be conducted in a specially adapted room instead of the usual clinical situation. Audio recording and feedback appeared an attractive alternative.

In a further study, students were randomly allocated to repeated practice followed by either video or audio feedback, and both under supervision. Both groups showed significant improvement in history-taking skills, and it was evident that much could be achieved through audio feedback.

\section{Conclusion}

From the above studies the following training programme would seem to be feasible and effective:

1. Students watch and discuss tapes on interviewing prepared by the Association of University Teachers of Psychiatry. These include a demonstration of how to interview as well as examples of how to deal with common difficulties.

2. They are next given a handout containing guidance about questions they should ask and techniques they should use, as well as a rating scale to help them to assess their own performance. 
3. They then form groups of four. Each of them is given a tape cassette recorder and records a short interview with a patient each week.

4. The student plays back his interview each week and rates it.

5. The group meets weekly, and one student's tape is played and discussed in the presence of a tutor.

The tutor ensures that each student has at least one chance to receive feedback.

When students fail to acquire certain skills or to experience difficulties, the tutor gives them feedback via video after they have had the chance to practise these skills.

\section{REFERENCES}

Goldberg, D. P., SteELE, J. J. \&. SMrth, C. Teaching psychiatric interview techniques to family doctors. Acta Psychiatrica Scandinavica, in press.

\footnotetext{
\& SPIVEY, L. (1980) Training family doctors to recognize poychiatric illness with increased accuracy. Lancet, ii, 521-3.

MAGUiRe, G. P. \& RUTteR, D. R. (1976) History-taking for medical students: 1. Deficiencies in performance. Lancet, $i$, 556-8.

CLARKE, D. \& JolleY, B. (1977) An experimental comparison of 3 courses in history-taking for medical students. Medical Education, 11, 175-82.

- Roe, P., Goldberg, D., Jones, S., Hyde, C. \& O'Dowd, T. (1978) The value of feedback in teaching interviewing still, to medical students. Psychological Medicine, 8, 695-704.

RUTteR, D. R. \& MAGUIRE, G. P. (1976) History-taking for medical students: II. Evaluation of a training programme. Lancet, $i i, 558$.

SANSON-Fisher, R. \& MAGuire, P. (1980) Should skills in communicating with patients be taught in medical schools? Lancet, ii, 523-7.
}

\section{Teaching Psychotherapy Skills to Postgraduate Psychiatrists \\ BY FranK Margison \\ University Hospital of South Manchester}

An assumption underlying this paper is that knowledge of psychotherapy should be available to all psychiatry trainees, not just to those with a special interest in psychotherapy. It does not, of course, follow that all trainees should practise psychotherapy throughout their careers, but they should know something about the therapeutic aspects of the doctorpatient relationship. These aspects are highlighted in psychotherapy but are by no means exclusive to it. Given this assumption, we are faced with the problem of how to provide this training - in terms of content and logistics.

The title of this paper, 'Teaching Psychotherapy Skills' implies a certain view of psychotherapy training: skills can be taught which have an immediate bearing on psychotherapy practice; it does not follow that the skills are psychotherapy, or even that they have yet been identified. One important consequence is a decision to develop effective and efficient ways of teaching psychotherapy by identifying those skills which make constructive change in the patient more likely.

This approach borrows from the behavioural tradition in so far as an attempt is made to analyse a task systematically: in this case, both a particular model of psychotherapy treatment and the separate task of teaching the component skills incorporated in this model.

However, it seems likely that factors not yet specified in the relationship between patient and therapist, and between therapist and supervisor, are also likely to be important
(Shapiro, 1980).

In view of this, do we need to specify any component skills in detail to teach psychotherapy? It can be argued that the effective agent in supervision is a relationship in which the trainee has the opportunity to discover and overcome his own difficulties in relating to his patients; the components that could be described as 'skills' would be viewed as secondary. Moreover, there is at present no definitive evidence which favours one model of psychotherapy supervision over any other at present. This matter is reviewed in Hess's recent book (Hess, 1980).

However, research in teaching medical interviewing skills to undergraduates has shown that certain skills are most efficiently taught with specific teaching methods-particularly giving the student foedback about interviewing behaviour within a conceptual framework (Maguire et al, 1978).

Research is in progress in the Manchester University Department of Psychiatry which attempts to examine similar areas in psychotherapy teaching. The project links three relevant questions:

1) Can we describe a plausible 'model' of psychotherapy which can be specified in terms of aims and therapist behaviour? This model should not, however, oversimplify the reality of clinical practice by overdetermining the responses a therapist might make.

2) After describing this model, do we know whether thera- 